\title{
Development of Persian version of the Spinal Cord Independence Measure III assessed by interview: a psychometric study
}

\author{
Hooshang Saberi ${ }^{1,2} \cdot$ Farzad Vosoughi $^{1,2} \cdot$ Nazi Derakhshanrad $^{1,2} \cdot$ Mirsaeed Yekaninejad $^{3} \cdot$ Zahid Hussain Khan $^{4}$. \\ Amir Hassan Kohan ${ }^{2} \cdot$ Shahriar Parvaneh ${ }^{5} \cdot$ Setareh Ghahari ${ }^{5} \cdot$ Fereydoon Agheli $^{2} \cdot$ Fardis Vosoughi $^{6}$
}

Received: 1 March 2018 / Revised: 27 April 2018 / Accepted: 28 April 2018 / Published online: 25 May 2018

(c) International Spinal Cord Society 2018

\begin{abstract}
Study design Cross-sectional psychometric study.

Objectives To translate the Spinal Cord Independence Measure III (SCIM-III) into Persian, to evaluate it culturally and to analyze the validity and reliability of the Persian version of the SCIM-III (P-SCIM).

Setting Brain and Spinal Injury Research Center (BASIR), Tehran, Iran.

Methods The P-SCIM was developed by forward translation, back-translation, and cultural equivalence assessment procedure. The authors studied: (a) correlation of P-SCIM with the Functional Independence Measure (FIM ${ }^{\mathrm{TM}}$ ) for determining convergence validity, (b) P-SCIM scores in neurological categories for comparison and evaluating discriminative validity, (c) Inter-rater reliability of P-SCIM, (d) Cronbach's alpha for measuring internal consistency of P-SCIM-III.

Results The validity of the scale was supported by a Pearson correlation coefficient of $>0.9(p<0.001)$ between FIM $^{\mathrm{TM}}$ and P-SCIM. The Persian SCIM was found to be valid in discriminating different neurological categories. The Inter-rater reliability was concluded by Intraclass correlations of a coefficient $>0.9$. Bland-Altman analysis demonstrated good agreement between our raters (mean difference: 0.7, limit of agreement: - 8.09-9.58). Also internal consistency of the scale was shown by Cronbach's alpha to be $>0.7(0.86)$.

Conclusion P-SCIM-III is a valid and consistent tool for determining functionality in Persian speaking people with spinal cord injury.
\end{abstract}

Data archiving There were no data to deposit.

Electronic supplementary material The online version of this article (https://doi.org/10.1038/s41393-018-0160-5) contains supplementary material, which is available to authorized users.

Hooshang Saberi

hgsaberi@yahoo.com

1 Department of Neurosurgery, Imam Khomeini Hospital, Tehran University of Medical Sciences, Tehran, Iran

2 Brain and Spinal cord injuries Research Center, Neuroscience Institute, Tehran University of Medical Sciences, Tehran, Iran

3 Department of Epidemiology and Biostatistics, School of Public Health, Tehran University of Medical Sciences, Tehran, Iran

4 Depatment of Anesthesiology, Imam Khomeini Hospital, Tehran University of Medical Sciences, Tehran, Iran

5 School of Rehabilitation Therapy, Queen Univiversity, Kingston, ON, Canada

6 Department of Orthopedic Surgery, Shariati Hospital, Tehran University of Medical Sciences, Tehran, Iran

\section{Introduction}

The cost burden on the health care system by the rehabilitation system and management of the related complications of spinal cord injury (SCI) is estimated to be 9.7 million dollars per year in the USA [1]. During the last 30 years, owing to improved care, the percentage of people surviving with complete lesions has risen to $50 \%$ and in tetraplegia to $33.3 \%$ among all people with traumatic SCI [2]. Given that SCI occurs mostly in those in the productive age groups and that there is a high cost placed on health care, arriving at the best therapeutic or rehabilitative management protocols for individuals with SCI is a priority. It remains undebatable that this goal could be done only with a valid and reliable functional tool [3]. Knowledge about the exact disability impact of SCI on an individual's life may pave the way for better planning in a national health care system.

As a scale for the functional assessment, the Spinal Cord Independence Measure (SCIM) is a well-known tool worldwide $[4,5]$. The latest version, SCIM-III, has been 
assessed in many multicenter trials to determine its validity and reliability [6, 7]. The comprehensive nature of SCIM-III provides patients and their caregivers with rehabilitation goals to be achieved, and motivates individuals with SCI to improve their level of independence by assessing their achievements that are important medically, socially, or psychologically [4].

In order to use the SCIM-III in a different language, not only do translations have to be performed, but also the tool should be adapted to measure the same concept in different cultural contexts and life styles. This process is known as cultural adaptation [8], and has been performed for the English version of SCIM-III successfully into many languages [9-13]. Traditionally, the Persian language, also called "Farsi", has two varieties called "Dari" and "Tajik". It is spoken by a noticeable population within several countries such as Iran, Tajikistan, Afghanistan, Azerbaijan, and many others in the Persian Gulf states like Bahrain, Iraq and the United Arab Emirates [14]. Therefore, developing a valid and reliable version of SCIMIII for Persian individuals with SCI seems to be a necessity. The aim of this study is to (a) develop the Persian version of SCIM-III (P-SCIM-III), and (b) evaluate its validity and consistency for Persian speaking participants with SCI.

\section{Methods}

\section{Participants}

This cross-sectional study was conducted from April 2015 to January 2017 on participants with SCI referred to our Center. Inclusion criteria were: (1) Persian language as mother tongue, (2) age between 18 and 60 years, and (3) disease chronicity of not $<1$ month. Those who had major comorbidities or complications, ASIA Impairement Scale (AIS) E cases, and those unable to speak owing to tracheostomy were excluded from the study. Out of 362 referred cases, a total of 279 participants were included in the study. The ethics committee of Tehran University of Medical Sciences approved the study, and informed consent was obtained from all participants.

\section{Instrument development}

SCIM-III was translated separately by two translators fluent in English and native in Persian (forward translation). Their comparison and panel discussion led to the primary Persian version. Two other translators fluent in Persian and native in English, not familiar with the scale, translated the Persian form back to English (backward translation). Another committee comprised of a neurosurgeon, an occupational therapist, two general practitioners, and an English literature professor compared the original English form, and the obtained form, to achieve the best Persian version by rejecting inappropriate words. The committee then ensured that the translation was fully comprehensive. The two forms were compared with ensure semantic, idiomatic, experiential, and conceptual equivalence. Thereafter in a pre-test the Persian form of the questionnaire was given to two general practitioners experienced in evaluating patients with SCI to measure functional status in 30 individuals to assure the fluency and feasibility of the Persian questionnaire. Thereafter, according to the comments by the practitioners, the final version of the P-SCIM was developed (Figure S1).

\section{Procedure}

The study was performed during a 2-year period in an outpatient rehabilitation setting admitting individuals with SCI for educational programs. After checking demographic data and neurological status of the clients, they were evaluated for inclusion and exclusion criteria. Two general practitioners (rater 1 and 2) registered the P-SCIM forms for the included cases. They were unaware of each other's assessment and were not involved in the treatment and management protocols of the participants. An occupational therapist (rater 3) educated in Functional Independence Measure $^{\mathrm{TM}}$ (FIM ${ }^{\mathrm{TM}}$ ) assessment, registered the FIM scores for each case separately. Each case was interviewed at least $30-45 \mathrm{~min}$ in a silent and relaxed environment. The scores were based on the participant's report of his/her daily activities. Raters did the measurement of each participant using the final Persian version of the SCIM, based on the most common form of activity during the last week at the site of residence. The results then were entered into SPSS software for Windows version 22, to perform statistical analysis.

\section{Analysis}

Analysis was conducted, calculating Inter-rater reliability and validity indices.

\section{Validity indices}

The developed P-SCIM was evaluated for convergence and discriminative validity. Convergence validity was obtained by means of the Pearson correlation coefficient between PSCIM and FIM results. A value of 0.9 or greater was assumed to be statistically significant. Discriminative validity was determined by comparing P-SCIM scores for neurological subcategories, using one way analysis of variance with Tukey method. 


\section{Reliability indices}

Inter-rater reliability was calculated employing Intraclass Correlation of Coefficience (ICC), total agreement, kappa coefficient, and Bland-Altman limit of agreement. Internal consistency was calculated using Cronbach's alpha, which was assumed reasonable for values $>0.7$ [15]. Kappa coefficient $>0.6$ [16], and ICC $>0.75$ [15] were assumed to be statistically acceptable. Bland-Altman analysis was performed by MedCalc ${ }^{\mathrm{TM}}$ software (version 8.6). A $p$ value $<0.05$ was considered to be statistically significant.

\section{Results}

\section{Epidemiologic and neurological findings}

Demographic characteristics, neurological level, and severity of SCI in the studied participants are shown in Table 1.

\section{Convergence validity}

The Pearson's correlation of coefficience between P-SCIM scores obtained by rater 1 and 2 , and FIM ${ }^{\mathrm{TM}}$ obtained by rater 3, was found to be 0.905 for rater 1 and 0.900 for rate $2(p<0.001)$.

\section{Discriminative validity}

As shown in Table 2, there was an incremental trend in PSCIM scores descending from level C1-C4 to T1-S5 and from AIS A, B, and C to AIS D. All the scores' differences between the above categories within subscales and total PSCIM were found to be statistically significant $(p<0.05)$. An exception was the difference between upper and lower cervical cases within all subscales, which was not significant $(p>0.05)$. Also, the scores of patients with AIS D and patients with "T1-S5, AIS A, B, C" subgroups, did not show significant differences for "self-care" and "mobility in room and toilet" subscales scores (Table 2, $p>0.05$ ).

\section{Reliability indices}

Within all subscales of P-SCIM, the ICC between raters 1 and 2 was acceptable ( $>0.75$ ) (Table 3$)$.

The total agreement between raters for each item was found to be acceptable ( $>80 \%$ ) in 16 out of 19 items, and unacceptable in three items; "grooming" (55.9\%), "sphincter management-bowel" $(76.7 \%)$, and "use of toilet" $(74.2 \%)$ (Table 4). Kappa coefficient between raters was statistically significant for all items (kappa $>0.6$ ), except for "grooming" (0.46, Table 4).
Table 1 Neurological and demographic variables of traumatic SCI

\begin{tabular}{ll}
\hline Variable & \\
Age (years), mean \pm SD & $33.70 \pm(10.13)$ \\
Formal education (years), mean \pm SD & $9.00 \pm(4.48)$ \\
Male/female ratio & $4 / 1$ \\
Etiology $n(\%)$ & \\
MVA & $143(51 \%)$ \\
Falling & $72(26 \%)$ \\
Sport injury & $35(12 \%)$ \\
Heavy drop & $18(6 \%)$ \\
Violence & $11(4 \%)$ \\
Lesion characteristics $n(\%)$ & \\
C1-C4: (AIS A, B, C) & $16(6) ;($ AIS D) $4(1.4)$ \\
C5-C8: (AIS A, B, C) & $55(20) ;($ AIS D) 3(1.1) \\
T1-S5: (AIS A, B, C) & $193(69) ;($ AIS D) $8(2.9)$ \\
& Total 279 \\
Time past injury in years, mean $\pm(S D)$ & $4.23(4.54)$
\end{tabular}

Abbreviations: $n$, number of patients studied; SD, standard deviation; MVA, motor vehicle accident; C, cervical; T, thoracic; S, sacral; AIS, American spinal injury association impairment score; TSCI, traumatic spinal cord injury

Using Bland-Altman analysis, the mean difference between rater 1 and 2 was 0.74 for the total scores (Table 5). In the same way, the mean differences between rater 1 and 2 in total scores stratified by age $(<26,26-32,32-40$, and $>$ 40 years), gender, education $(<6,6-12$, and $>12$ years of formal education), neurological level subgroup, and time since injury ( $<6$ months, $>6$ months) were measured. Time stratum ( $<6$ months since trauma) had the greatest mean difference (2.18 score), whereas those aged 32-40 years showed the least mean score difference $(0.03)$ between raters 1 and 2. The mean difference for other strata (neurological level subgroups, AIS, education years subgroup, and gender) did not show statistical significance $(p>0.05)$.

Cronbach's alpha for internal consistency was calculated to be 0.866 for rater 1 , and 0.868 for rater 2 . The obtained Cronbach's alpha decreased by all item deletion except for three items: "respiration", "mobility in bed", and "transfers ground to wheelchair".

\section{Discussion}

The SCIM-III has been accepted as the most valid assessment tool for individuals with SCI worldwide [17]. Until now, functional independence of patients measured by SCIM-III has been assessed either by observation of their performance, interviewing them, or self-report method. All the three methods have been valid and reliable options, but the highest agreement belongs to observation [7] and the lowest, to self-report [18, 19]. The observation method has 
Table 2 Validity of P-SCIM III discriminating severity categories

\begin{tabular}{lllll}
\hline Subscales & Severity categories & $N$ & Mean \pm SD & Significance \\
\hline Self-care & C1-C4:(AIS A,B,C) & 16 & $2.50 \pm 5.03$ & $P<0.001$ \\
& C5-C8:(AIS A,B,C) & 55 & $5.13 \pm 6.33$ & \\
& T1-S5:(AIS A,B,C) & 193 & $14.16 \pm 3.89$ & \\
& AIS D & 15 & $14.73 \pm 7.44$ & \\
Respiration and sphincter management & C1-C4:(AIS A,B,C) & 16 & $13.56 \pm 4.23$ & $P<0.001$ \\
& C5-C8:(AIS A,B,C) & 55 & $14.25 \pm 6.33$ & \\
& T1-S5:(AIS A,B,C) & 193 & $20.67 \pm 7.39$ & \\
Mobility in room and toilet & AIS D & 15 & $26.00 \pm 9.30$ & \\
& C1-C4:(AIS A,B,C) & 16 & $1.75 \pm 3.57$ & $P<0.001$ \\
& C5-C8:(AIS A,B,C) & 55 & $2.82 \pm 3.23$ & \\
T1-S5:(AIS A,B,C) & 193 & $7.20 \pm 2.80$ & \\
Mobility indoors and outdoors & AIS D & 15 & $8.87 \pm 2.33$ & \\
& C1-C4:(AIS A,B,C) & 16 & $2.25 \pm 4.77$ & $P<0.001$ \\
& C5-C8:(AIS A,B,C) & 55 & $2.11 \pm 3.31$ & \\
& T1-S5:(AIS A,B,C) & 193 & $5.91 \pm 4.94$ & \\
AIS D & 15 & $21.00 \pm 8.50$ & \\
Total P-SCIM & C1-C4:(AIS A,B,C) & 16 & $20.06 \pm 16.48$ & $P<0.001$ \\
& C5-C8:(AIS A,B,C) & 55 & $24.22 \pm 17.64$ & \\
& T1-S5:(AIS A,B,C) & 193 & $48.02 \pm 16.23$ & \\
& AIS D & 15 & $70.67 \pm 23.71$ & \\
& f & & \\
& & &
\end{tabular}

Abbreviations: P-SCIM, Persian version of Spinal Cord Independence Measure; $N$, number of participants; $\mathrm{SD}$, standard deviation; AIS, American Spinal injury Association Impairment Scale
Table 3 Intraclass correlation between raters 1 and 2 within P-SCIM III subscales and total scores

\begin{tabular}{ll}
\hline Subscale & Intraclass correlation (ICC, 95\% CI) \\
\hline $\begin{array}{l}\text { Self-care } \\
\text { Respiration and sphincter }\end{array}$ & $0.968(0.960-0.975)$ \\
$\begin{array}{l}\text { management } \\
\text { Mobility in the room and } \\
\text { toilet }\end{array}$ & $0.953(0.904-0.939)$ \\
$\begin{array}{l}\text { Mobility indoors and } \\
\text { outdoors }\end{array}$ & $0.980(0.974-0.984)$ \\
Total scores & $0.977(0.971-0.98277767)$
\end{tabular}

Abbreviations: CI, confidence interval; ICC, Intraclass correlation

been reliable but time consuming, whereas interview has both acceptable reliability and is less time consuming [20]. Therefore, many outpatient centers perform their assessments by the interview method [21, 22].

The SCIM-III has been adapted for Portuguese [9], Italian [11], Thai [13], Greek [23], Spanish [10], and Turkish [12] languages with favorable results. These adaptations are in line with cultural adaptation and translation of assessment scales, a process previously well described [8]. In the same way these processes have been conducted previously for translation of other SCI-related questionnaires and scales into the Persian language [24-26]. Discriminative validity of Turkish [12] and Thai [13] versions of SCIM-III have previously been demonstrated, and the same was shown in our study for P-SCIM. We used the neurological categories as proposed by DeVivo et al. [27] to establish discriminative validity of the P-SCIM. Our findings also reveal that P-SCIM has the validity to discriminate participants based on their neurological severity categories (Table 2).

The obtained Cronbach's alphas of P-SCIM in our study to evaluate internal consistency of the test were close to the previously reported values for the English SCIM-III [6, 7, 28, 29]. As previously demonstrated in the English SCIMIII $[2,7,23]$, the Cronbach's alpha and internal consistency of the P-SCIM subscale "Respiration and Sphincter Management" increases when the "respiration" item is deleted from the subscale $[6,7,28]$. Regarding the "Mobility in room and toilet" subscale, we observed that deletion of the "Mobility in bed" item increases the Cronbach's alpha. These findings have been reported during evaluation of English and Turkish versions [6, 7, 12, 28]. This finding may be because "respiration" and "mobility in bed" item scores may remain constant for many neurological levels below the high cervical area with different independence scores. Studies on Italian and Spanish versions have shown the mentioned feature in subscale "Respiration and Sphincter Management" only after deletion of the "Respiration" item $[10,11]$. At the same time, the papers on Thai and Portuguese versions of SCIM, have not reported "alpha if item deleted" analysis at all. 
Until now, functional independence of individuals with SCI measured by SCIM-III has been assessed either by observation of their performance, interviewing them, or self-report method.

Regarding the mean of differences (0.7), between rater 1 and 2 for total P-SCIM scores in different cases assessed by Bland-Altman method, it was very small, although statisti-

Table 4 Total agreement and kappa coefficients between raters on different P-SCIM III's items

\begin{tabular}{|c|c|c|c|c|}
\hline Task & $\begin{array}{l}\text { Total } \\
\text { agreement }\end{array}$ & $\begin{array}{l}\text { Two point } \\
\text { difference } \\
\text { agreement }\end{array}$ & Kappa & $95 \% \mathrm{CI}$ \\
\hline \multicolumn{5}{|l|}{ Self- care } \\
\hline Feeding & 94.6 & 99.6 & 0.860 & $0.74-0.98$ \\
\hline Bathing upper body & 84.9 & 100 & 0.746 & $0.68-0.82$ \\
\hline Bathing lower body & 84.6 & 100 & 0.767 & $0.70-0.83$ \\
\hline Dressing upper body & 93.5 & 97.1 & 0.863 & $0.80-0.92$ \\
\hline Dressing lower body & 82.8 & 96.1 & 0.752 & $0.69-0.81$ \\
\hline Grooming & 55.9 & 100 & 0.458 & $0.40-0.52$ \\
\hline \multicolumn{5}{|c|}{ Respiration and sphincter management } \\
\hline Respiration & 93.5 & 99.6 & 0.814 & $0.73-0.90$ \\
\hline $\begin{array}{l}\text { Sphincter } \\
\text { management-bladder }\end{array}$ & 86.4 & 87.8 & 0.817 & $0.76-0.87$ \\
\hline $\begin{array}{l}\text { Sphincter } \\
\text { management-bowel }\end{array}$ & 76.7 & 82.4 & 0.637 & $0.56-0.71$ \\
\hline Use of toilet & 74.2 & 98.6 & 0.648 & $0.58-0.71$ \\
\hline \multicolumn{5}{|c|}{ Mobility in room and toilet } \\
\hline Mobility in bed & 87.5 & 98.6 & 0.781 & $0.72-0.85$ \\
\hline $\begin{array}{l}\text { Transfers bed/ } \\
\text { wheelchair }\end{array}$ & 90.7 & 100 & 0.857 & $0.80-0.91$ \\
\hline $\begin{array}{l}\text { Transfers wheelchair/ } \\
\text { toilet/tub }\end{array}$ & 88.5 & 100 & 0.817 & $0.76-0.88$ \\
\hline \multicolumn{5}{|c|}{ Mobility indoors and outdoors } \\
\hline Mobility indoors & 90.3 & 99.6 & 0.848 & $0.79-0.90$ \\
\hline $\begin{array}{l}\text { Mobility moderate } \\
\text { distance }\end{array}$ & 86.4 & 100 & 0.806 & $0.75-0.86$ \\
\hline Mobility outdoors & 82.1 & 99.3 & 0.734 & $0.67-0.80$ \\
\hline Stair management & 96.8 & 100 & 0.867 & $0.79-0.95$ \\
\hline $\begin{array}{l}\text { Transfers wheelchair/ } \\
\text { car }\end{array}$ & 91.0 & 100 & 0.848 & $0.79-0.90$ \\
\hline $\begin{array}{l}\text { Transfers ground/ } \\
\text { wheelchair }\end{array}$ & 95.3 & 100 & 0.877 & $0.81-0.94$ \\
\hline
\end{tabular}

Abbreviations: P-SCIM III, Persian version of Spinal Cord Independence Measure; CI, confidence interval cally significant $(p<0.05$, Table 5). Our inter-rater reliability indices [ICCs (Table 3) and kappa coefficients (Table 4) of P-SCIM] were close to the results reported for the English SCIM-III obtained by observation method $[6,7,28,29]$. Therefore, our rapid interview method results may be comparable with the more time consuming observation method.

The obtained kappa coefficients of P-SCIM (Table 4) had more than acceptable standard values (0.6) for most items. All the corresponding values for the English SCIM-III assessed by interview have been $<0.6$ except for the two items: ground/bed to wheelchair. This discrepancy could be due to the method of interview, i.e., in our study, each individual was evaluated by the raters with the same profession, whereas in the Itzkovich 2017 study [19], participants were assessed by raters with different professions (occupational therapist and physiotherapist). Also, our large sample size may be another explanation for this difference (279 vs 19).

Ackerman et al. [30] have reported some SCIM-III items either to have a floor effect: "transfer ground to wheelchair" and "stair management", or ceiling effect: "respiration". We have had the same observations; floor effect for the items "stair management (86\%); and "transfer ground to wheelchair (74\%)", and ceiling effect for items "respiration $(81.4 \%)$ " and "feeding (77.4\%)".

Although SCIM-III has sufficient reliability indices, nevertheless many studies also have proposed that developing a 'training manual' of SCIM-III can promote its reliability [30, 31] further. Developing a manual for $\mathrm{P}$ SCIM may be a good horizon for future work.

Among the limitations of our study we note that the etiology of SCI in our participants was restricted to those with traumatic injuries, which could limit the generalizability of our results. Most studies have considered a mixed population [6, 7, 10-13, 29]. Further studies to evaluate P-SCIM in non traumatic SCI may be necessary. Future studies may be necessary to evaluate "sensitivity to functional changes" and "intra-rater reliability" indices further, and to assess the appropriateness of P-SCIM for practical clinical application.
Table 5 Bland-Altman mean differences: limit of agreements between rater 1 and 2 within $\mathrm{P}$ SCIM III subscales and total scores

\begin{tabular}{llll}
\hline Subscale & \multicolumn{3}{l}{ Bland-Altman difference } \\
\cline { 2 - 4 } & Mean & $95 \%$ CI & LOA \\
\hline Self-care & 0.29 & $+0.10-+0.48$ & $-2.80-+3.38$ \\
Respiration and sphincter management & 0.66 & $+0.29-+1.02$ & $-5.39-+6.71$ \\
Mobility in the room and toilet & 0.06 & $-0.07-+0.19$ & $-2.11-+2.23$ \\
Mobility indoors and outdoors & 0.23 & $-0.08-+0.37$ & $-2.26-+2.72$ \\
Total scores & 0.74 & $+0.21-+1.28$ & $-8.09-+9.58$ \\
\hline
\end{tabular}

Abbreviations: P-SCIM, Persian version of Spinal Cord Independence Measure; CI, confidence interval; LOA, limit of agreement 


\section{Conclusion}

Our study suggests that the P-SCIM (Appendix 1) is a valid and reliable measurement scale for individuals with traumatic SCI. P-SCIM may be useful for Persian speaking health professionals who may not be fluent in English. Further multicenter trials may be necessary to obtain more concrete evidence about the validity and reliability of the questionnaire.

Acknowledgements We acknowledge the developers of SCIM for their permission to use their scale in the current study. Also We thank the participants for their kind participation in the study. We are indebted to Parastoo Saberi for preparing the supplementary figure.

Author contributions H.S. was responsible for conduction of the study, neurological evaluations and preparing the manuscript. F.V. was responsible for data analysis, and manuscript preparation. N.D. was responsible for registering SCIM, and manuscript preparation. M. Y. was responsible for statistical analysis of the data and methodology consult. Z.H.K. was responsible for backward translation, manuscript review. A.H.K. was responsible for registering FIM. S.P. was responsible for consulted for forward translation, and a consent was sought for English to Persian Translation. S.G. was responsible for consulting translation. A.F. was responsible for forward translation. F. $\mathrm{V}$ was responsible for registering SCIM.

Funding This study was conducted without funding or sponsorship.

\section{Compliance with ethical standards}

Conflict of interest The authors declare that they have no conflict of interest.

\section{References}

1. Berkowitz MOLP, Kruse D, Harvey C. Spinal Cord Injury: An Analysis of Medical and Social Costs. New York: Demos Medical Publishing Inc; 1998.

2. Wyndaele M, Wyndaele JJ. Incidence, prevalence and epidemiology of spinal cord injury: what learns a worldwide literature survey? Spinal Cord. 2006;44:523-9.

3. Fitzpatrick R, Fletcher A, Gore S, Jones D, Spiegelhalter D, Cox D. Quality of life measures in health care. I: Applications and issues in assessment. BMJ. 1992;305:1074-7.

4. Catz A, Itzkovich M. Spinal Cord Independence Measure: comprehensive ability rating scale for the spinal cord lesion patient. J Rehabil Res Dev. 2007;44:65-8.

5. Catz A, Itzkovich M, Agranov E, Ring H, Tamir A. SCIM--spinal cord independence measure: a new disability scale for patients with spinal cord lesions. Spinal Cord. 1997;35:850-6.

6. Anderson KD, Acuff ME, Arp BG, Backus D, Chun S, Fisher K, et al. United States (US) multi-center study to assess the validity and reliability of the Spinal Cord Independence Measure (SCIM III). Spinal Cord. 2011;49:880-5.

7. Itzkovich M, Gelernter I, Biering-Sorensen F, Weeks C, Laramee MT, Craven BC, et al. The Spinal Cord Independence Measure (SCIM) version III: reliability and validity in a multi-center international study. Disabil Rehabil. 2007;29:1926-33.

8. Guillemin F, Bombardier C, Beaton D. Cross-cultural adaptation of health-related quality of life measures: Literature review and proposed guidelines. J Clin Epidemiol. 1993;46:1417-32.
9. Riberto M, Tavares DA, Rimoli JR, Castineira CP, Dias RV, Franzoi AC, et al. Validation of the Brazilian version of the Spinal Cord Independence Measure III. Arq Neuropsiquiatr. 2014;72: 439-44.

10. Zarco-Perinan MJ, Barrera-Chacon MJ, Garcia-Obrero I, MendezFerrer JB, Alarcon LE, Echevarria-Ruiz, de Vargas C. Development of the Spanish version of the Spinal Cord Independence Measure version III: cross-cultural adaptation and reliability and validity study. Disabil Rehabil. 2014;36:1644-51.

11. Invernizzi M, Carda S, Milani P, Mattana F, Fletzer D, Iolascon $\mathrm{G}$, et al. Development and validation of the Italian version of the Spinal Cord Independence Measure III. Disabil Rehabil. 2010;32: 1194-203.

12. Unalan H, Misirlioglu TO, Erhan B, Akyuz M, Gunduz B, Irgi E, et al. Validity and reliability study of the Turkish version of Spinal Cord Independence Measure-III. Spinal Cord. 2015;53: 455-60.

13. Wannapakhe J, Saensook W, Keawjoho C, Amatachaya S. Reliability and discriminative ability of the spinal cord independence measure III (Thai version). Spinal Cord. 2016;54:213-20.

14. Wikipedia. Persian Language Geography. Wikipedia 2018.

15. Marino RJSM. Functional assessment in spinal cord injury. Top Spinal Cord Inj Rehabil. 1996;1:32-45.

16. McHugh ML. Inter-rater reliability: the kappa statistic. Biochem Med. 2012;22:276-82.

17. Anderson K, Aito S, Atkins M, Biering-Sorensen F, Charlifue S, Curt A, et al. Functional recovery measures for spinal cord injury: An evidence-based review for clinical practice and research. J Spinal Cord Med. 2008;31:133-44.

18. Fekete C, Eriks-Hoogland I, Baumberger M, Catz A, Itzkovich M, Luthi $\mathrm{H}$, et al. Development and validation of a self-report version of the Spinal Cord Independence Measure (SCIM III). Spinal Cord. 2013;51:40-7.

19. Itzkovich M, Shefler H, Front L, Gur-Pollack R, Elkayam K, Bluvshtein V, et al. SCIM III (Spinal Cord Independence Measure version III): reliability of assessment by interview and comparison with assessment by observation. Spinal Cord. 2017;56:46-51.

20. Itzkovich M, Tamir A, Philo O, Steinberg F, Ronen J, Spasser R, et al. Reliability of the Catz-Itzkovich Spinal Cord Independence Measure assessment by interview and comparison with observation. Am J Phys Med Rehabil. 2003;82:267-72.

21. Derakhshanrad N, Vosoughi F, Yekaninejad MS, Moshayedi P, Saberi H. Functional impact of multidisciplinary outpatient program on patients with chronic complete spinal cord injury. Spinal Cord. 2015;53:860-5.

22. Derakhshanrad N, Yekaninejad MS, Vosoughi F, Sadeghi Fazel F, Saberi H. Epidemiological study of traumatic spinal cord injuries: experience from a specialized spine center in Iran. Spinal Cord. 2016;54:901-7.

23. Michailidou CML, De Souza LH. Translation into Greek and initial validity and reliability testing of a modified version of the SCIM III, in both English and Greek, for self-use. Disabil Rehabil. 2016;38:180-8.

24. Hadian MR, Yekaninejad MS, Salehin F, Razavi SH, Javidan AN, Pakpour AH, et al. Cross-cultural adaptation and reliability evaluation of Iranian version of Functional Assessment Measure in spinal cord injury patients. Neurol Neurochir Pol. 2012;46: 351-6.

25. Naghdi S, Ansari NN, Raji P, Shamili A, Amini M, Hasson S. Cross-cultural validation of the Persian version of the Functional Independence Measure for patients with stroke. Disabil Rehabil. 2016;38:289-98.

26. Motamed N, Ayatollahi AR, Zare N, Sadeghi-Hassanabadi A. Validity and reliability of the Persian translation of the SF-36 version 2 questionnaire. East Mediterr Health J. 2005;11:349-57. 
27. DeVivo MJ, Biering-Sorensen F, New P, Chen Y. Standardization of data analysis and reporting of results from the International Spinal Cord Injury Core Data Set. Spinal Cord. 2011;49:596-9.

28. Bluvshtein V, Front L, Itzkovich M, Aidinoff E, Gelernter I, Hart $\mathrm{J}$, et al. SCIM III is reliable and valid in a separate analysis for traumatic spinal cord lesions. Spinal Cord. 2011;49:292-6.

29. Glass CA, Tesio L, Itzkovich M, Soni BM, Silva P, Mecci M, et al. Spinal Cord Independence Measure, version III: Applicability to the UK spinal cord injured population. J Rehabil Med. 2009;41:723-8.

30. Ackerman P, Morrison SA, McDowell S, Vazquez L. Using the Spinal Cord Independence Measure III to measure functional recovery in a post-acute spinal cord injury program. Spinal Cord. 2010;48:380-7.

31. Harvey LA, Anderson KD. The spinal cord independence measure. J Physiother. 2015;61:99. 